\title{
Difficulty in emotional regulation and pain in the elderly
}

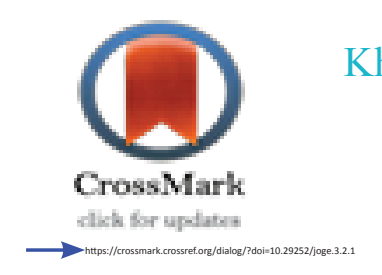

\section{Khanzadeh $\mathrm{M}^{1}$, ${ }^{*}$ Aminimanesh $\mathrm{S}^{2}$, Aghamohammadi $\mathrm{S}^{3}$}

1- Department of Psychology, Feizoleslam Non - Governmental Non - Profit Institute of Higher Education, Khomeinishahr, Isfahan, Iran.

2- Department of Psychology, Shiraz Branch, Islamic Azad University, Shiraz, Iran (Correspondent Author)

E-mail: sajadaminimanesh@gmail.com

3- Department of Psychology, Feizoleslam Non - Governmental Non - Profit Institute of Higher Education, Khomeinishahr, Isfahan, Iran

\section{Abstract}

Introduction: Pain is a complex experience that is not only determined by the intensity of stimulation of pain receptors, but is a multi-dimensional phenomenon that affects psychological factors, such as emotional regulation, except for biological factors. In this regard, the purpose of this study was to investigate the predicting role of the difficulties in emotional regulation on the duration of persistence and intensity of perceived pain in the elderly and the structural relationships between emotional regulation and the general severity of pain perception in these individuals.

Method: The present research is a correlation study. The sample consisted of 251 elderly who had pain in at least one area of their body. This sample was selected using a multi-stage purposeful sampling method from among the elderly in the Centers of daily aging in Shiraz. To collect data, the Persian version of the Difficulties in Emotional Regulation Scale (DERS), the McGill Pain Questionnaire and Pain Information Questionnaire were used. Data were analyzed by correlation, regression, and structural equation modeling method using SPSS 18 and LISREL 8.80 software.

Results: The results of regression showed that among components of difficulty in emotional regulation, limited access to strategies, difficulty in achieving goals and lack of emotional awareness, predict the overall severity of pain perception, and limited access to strategies can predict pain duration in elderly. Also, structural equation modeling results showed that the difficulties in emotional regulation is related to the general severity of pain perception in the elderly and can affect it $(\mathrm{R} 2=0.11)$.

Conclusion: In general, according to the findings of this study, it can be said that the components of difficulty in emotional regulation can predict elderly pain perception and these two construction are structurally related. These results can have various theoretical and practical implications in identifying the factors associated with aging pain perception and pain control in these individuals.

Keywords: Emotional regulation, Pain Severity, Aging.

Received: 12 October 2018

Accepted: 6 December 2018

\begin{tabular}{|l|l|}
\hline \multicolumn{3}{|c|}{ Access this article online } \\
\hline
\end{tabular}




\title{
دشوارى در نظم بخشى هيجانى و درد در سالمندان
}

\author{
مصطفى خانز اده'، "*سجاد امينى منش"، سميه آقامحمدى" \\ 1- استاديار، كروه روانشناسى، مؤسسه آموزش عالى غيردولتى -غير انتفاعى فيض الاسلام، خمينى شهر، اصفهان، ايران.

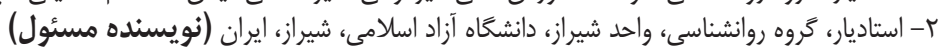 \\ يست الكترونيكى: sajadaminimanesh@gmail.com \\ ب- استاديار، كروه روانشناسى، مؤسسه آموزش عالى غيردولتى -غير انتفاعى فيض الاسلام، خمينى شهر، اصفهان، ايران.

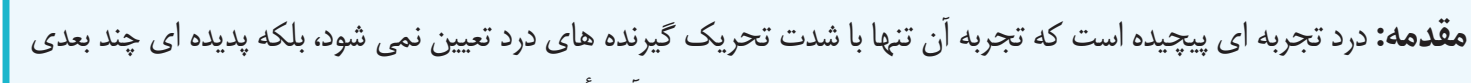

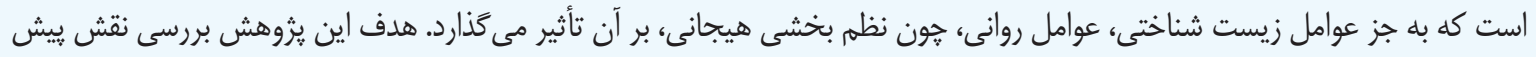

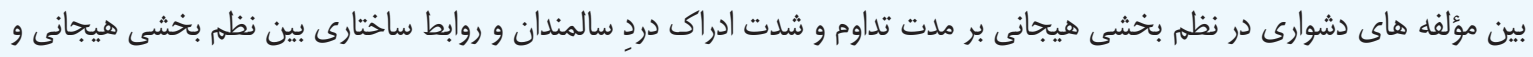
شدت كلى ادراك درد در اين افراد بود.

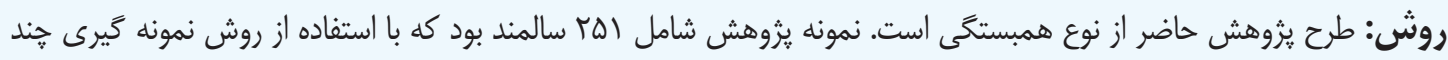

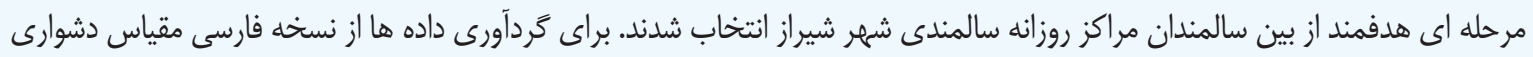

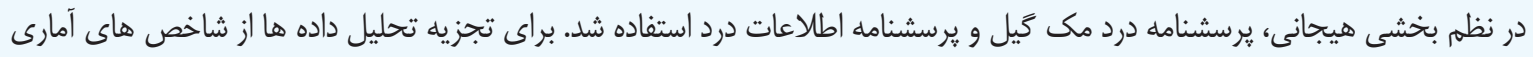

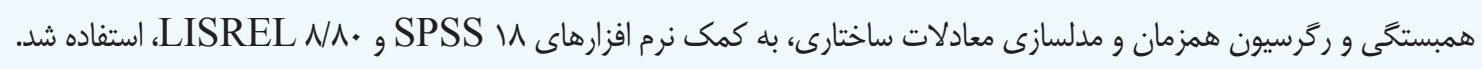

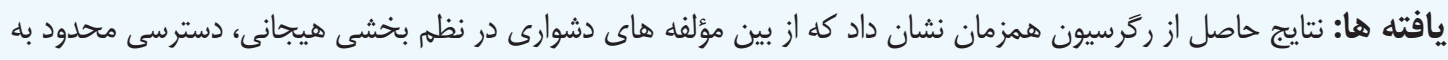

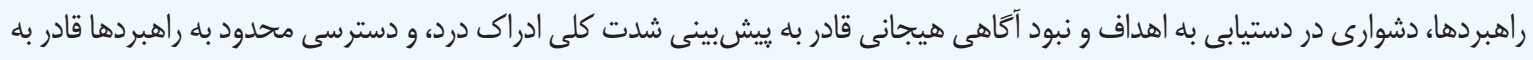

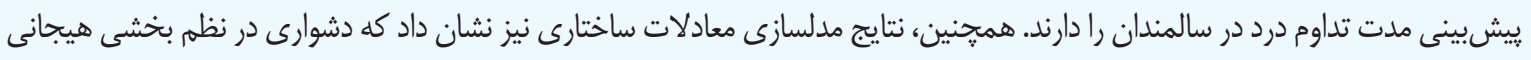

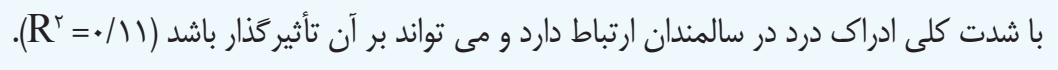

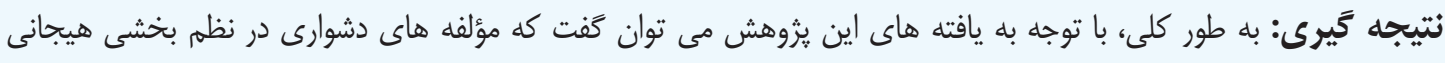

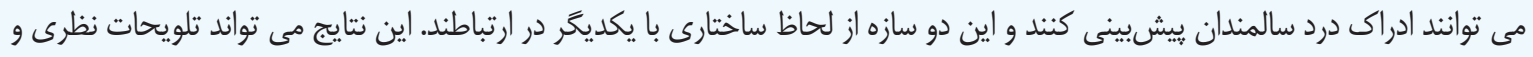

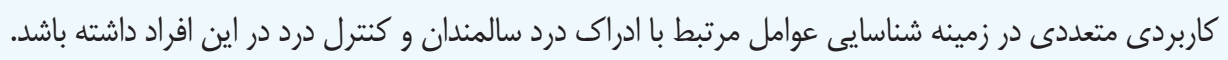
كليد وازه ها: نظه بخشى هيجانى، شدت درد، سالمندى. زمئه 
مى كنند و منجر به بروز پاسخ هاى رفتارى و فيزيولوزيك مى شوند

در زمينه تأثير هيجانات بر تعديل و تنظيم درد، بسيارى از يزوهش ها نشان داده اند كه نوسانات درد به سهولت تحت تأثير هيجانات قرار مى كيرند، به كونه اي كه هيجانات خوشايند عموماً منجر به كاهش دردمى شوند، در حالى كه هيجانات ناخوشايند شدت درد را افزايش مى دهند (T) ا). نظم بخشى هيجانى به عنوان فرايندى در نظر كرفته مى شود كه ازطريق آن فرد هيجانات خود را براى ياسخ متناسب بهان به خواسته هاى محيطى به طور هشيار يا ناهشيار تعديل و تنظيم

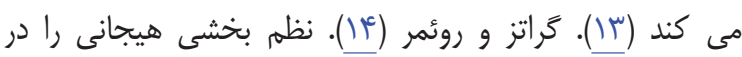

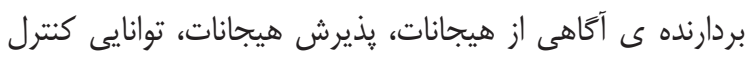

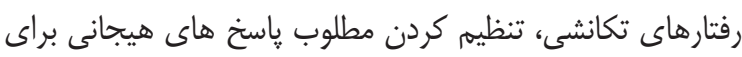

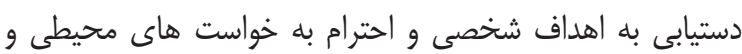
رفتاركردن مطابق با اهداف مطلوب در زمانى كه هيجان منفى احتى تجربه مى شود تعريف مى كنند. مى توان كفت تدابيرى كه افراد براى نظم بخشى هيجانى

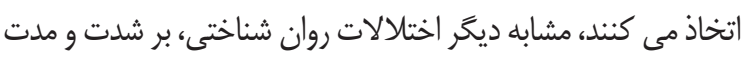
زمان تداوم درد مؤثر است. بسيارى از يزوهش ها همسو با هم نشان رئن داده اند كه نظه بخشى هيجانى و مؤلفه هاى آن به طور مستقيم شدت، فراوانى و طول دوره ى ادراك درد را تحت تأثير قرار مى دهد بان طان

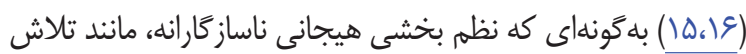

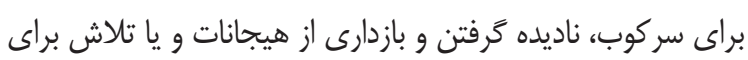

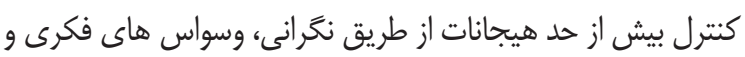
فاجعه سازى، منجر به افزايش شدت و ادراك درد مى شود. مطالعات انجام شده نشان مىدهند برخوردار بودن از مهارتهاى نظمبخشى منارئ

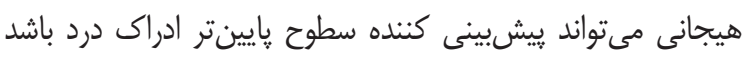

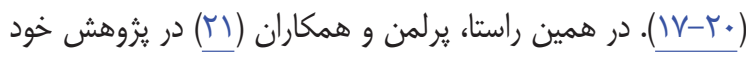
نشان دادند كه مداخلات مبتنى بر هيجان براى مبتلايان به اختلال درد بر سازوكارهاى نظهبخشى هيجانى و متعاقب آن بر ادراك درد

$$
\text { در آنها تأثير مى كذارد. }
$$

با توجه به افزايش اميد به زندگى افراد و همجنين ارتقاى بهداشت عمومى و خدمات يزشكى، مخصوصاً در دها هاى اخئ اخير،

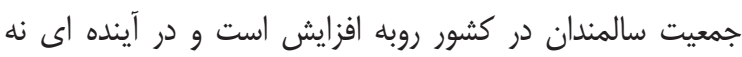
جندان دور درصد قابل توجهى از جمعيت عمومى كشور را سالمندان تشكيل خواهند داد. به علاوه، اختلالات مربوط به درد در سالمندان

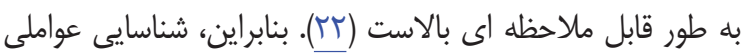

\section{مقالهمه}

درد از رايج ترين شكايت در سالمندان است كه تأثيرات شديدى بر كيفيت زندكى آنها دارد (لِ). درد تجربه الى يِيجيده

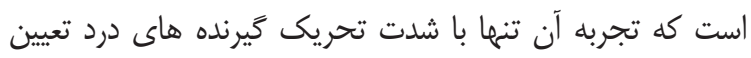

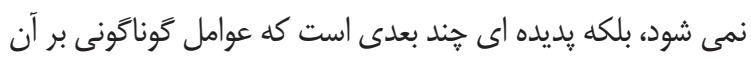

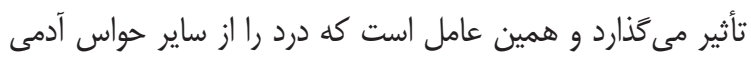
متمايز مى كند (؟). انجمن بين المللى مطالعات درد، درد را يك اليى

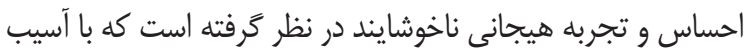
بافتى واقعى يا بالقوه در ارتباط است (ِّ).

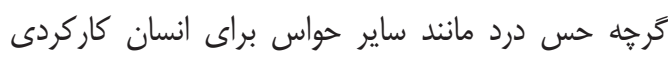
حياتى دارد و بقاى انسان را تضمين مى كند، اما زمانى كه شدت

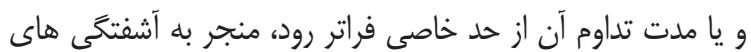

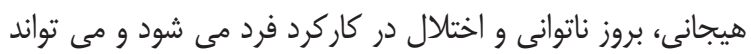

هزينه هاى سنخينى براى فردو جامعه در بر داشته باشد (ـأ). نتايج يزوهش ها در زمينه شيوع اختلال درد در سنين بناي

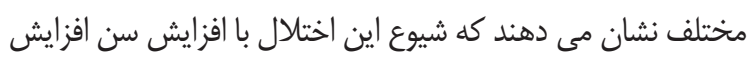

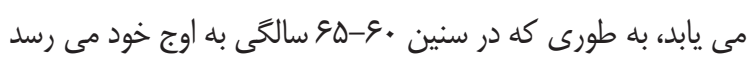

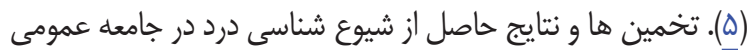
نشان مى دهد كه هr تا.ه درصد از سالمندان به شكلى از اختلال

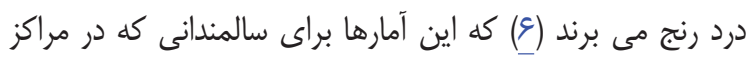

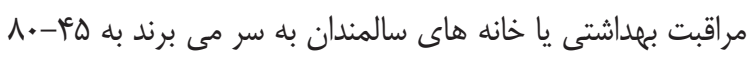
درصد مى رسد (V). بدون شك يكى از علل افزايش شيوع اختلال درد در سالمندان افزايش تعداد بيماريها و شرايط يزشكى خاصى است كه به طور همزمان در اين دوره به وجود مى آيد (ᄉ). در دوران سالمندى مسائل يبيجيده ى متعددى مى تواند تجربه هيجانى درد را

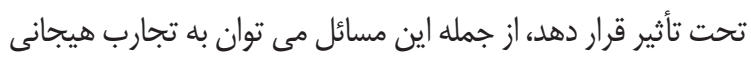

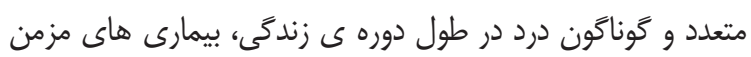

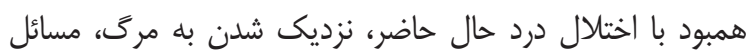

مرتبط با وابستخى به ديخران و حمايت خانواده اشاره نمود (9). نظريه بردازان معاصر بر نقش هيجانات در آماده سازى فرد براى ارائه واكنش هاى رفتارى، حركتى و فيزيولوزيكى در تسهيل

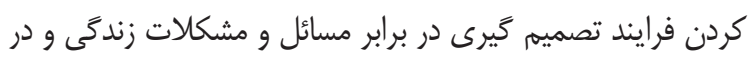

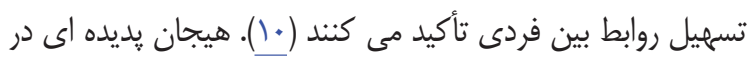
نظر كَرفته مى شود كه از سه جزء احساسى، رفتارى و فيزيولوزيكى تشكيل شده است و به واسطه موقعيت ها برانخيخته و منجر به تغيير جهت توجه مى شوند، سيستم ارزيابى شناختى را در فرد فعال 
است (عاب). در اين يزوهش نيز، اعتبار همسانى درونى زير مقياس ها

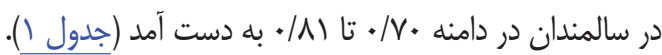
r- يرسشنامه درد مك گيل (MPQ ) مقياس ادراك درد شامل •r مجموعه كلمه است كه جهار بعد درد عاطفى، درد حسى، ارزيابى درد و دردهاى گَوناگون و شدت كلى درد را اندازه گيرى مى كند. فرد با توجه به ادراك خود از تجربه درد فعلى كلمه مورد نظر را در هر مجموعه انتخاب مى كند كه با توجه به ترتيب كلمات، شدت لهربه درد از بالا به يايين، نمره كذارى مى شود. بسيارى از يخوهش ها روايى و پايايى اين קرسشنامه را در حد مطلوبى عنوان نموده اند. براى مثال ترك، رادى و سالووى (ها) اعتبار آن را سه/· و ميلر

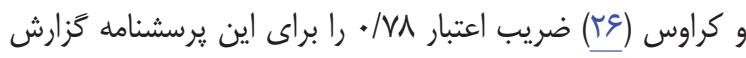
كردند. در ايران، روايى ملاكى و اعتبار اين يرسشنامه در سالمندان توسط خانزاده (TV) بررسى شده است. نتايج اين يثوهش نشان داد كه ابعاد اين يرسشنامه با يك مقياس خودسنجى درد، كه در آن فرد شدت درد خود را از • تا • ا نمره گذارى مى كند، همبستخى بين اع/• تا ای/• دارد. همجنين، در اين يُوهش ضريب آلفاى كرونباخ و اعتبار بازآزمايى یِ از دو هفته براى ابعاد يرسشنامه به ترتيب در

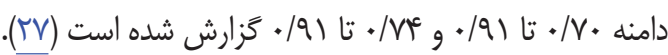
"- يرسشنامه جمعيت شناختى و اطلاعات درد: اين يرسشنامه محقق ساخته شامل سوالات و گَويه هايى بود كه علاوه بر اطلاعات مربوط به درد سالمند، شامل مدت زمان بروز درد، شدت درد، ناحيه درد و علت درد، اطلاعات جمعيت شناختى آنها، شامل سن، جنس و تحصيلات، را بررسى مى كرد. از اين يرسشنامه براى انتخاب نمونه با توجه به ملاكهاى ورود و خروج يزوهش استفاده شد. براى تجزيه و تحليل داده هاى يزوهش روش هاى آمارى همبستخى، رگرسيون خُندگانه و مدلسازى معادلات ساختارى از

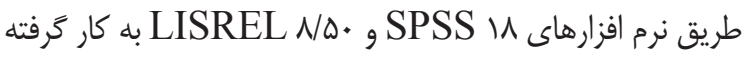

\section{كأفته هن}

نتايج بررسى نمونه نشان داد كه از بين افراد گروه نمونه، تعداد

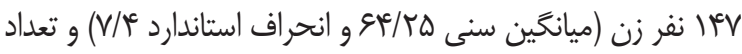

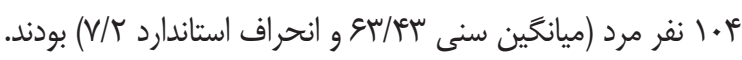

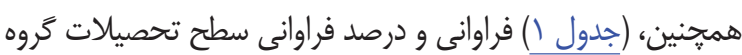
نمونه را به تفكيك جنسيت نشان مى دهد.
كه مى توانند بر ادراك درد در آنها تأثير بحذارد، ضرورى است. در همين راستا، يزوهش حاضر نيز به بررسى ارتباط بين دشوارى در نظم بخشى هيجانى بر مدت و شدت ادراك درد سالمندان يرداخته است.

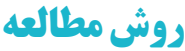

طرح يزوهش حاضر از نوع توصيفى-تحليلى است. جامعه

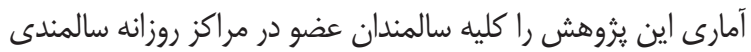
شهر شيراز در سال • وسا تشكيل مى داد. براى ورود افراد به جمع افراد به جمع شركت كنندكان در يُوهش، جندين ملاك در نظر كرفته شد كه عبارت بود از داشتن حداقل هه سال سن، داشتن درد حداقل در يك ناحيه از بدن، نداشتن بيمارى هاى اضمحلال كننده شناختى مانند دمانس و داشتن حداقل سواد سيكل. براى انتخاب نمونه از روش نمونه گيرى دردسترس استفاده شد؛ بدين صورت كه ابتدا تعداد • •ه يرسشنامه بين سالمندان توزيع شد و سيس با توجه به ملاك هاى ورود، تعداد عمب مورد از آنها كه داراى ملاك هاى يثوهش بودند انتخاب شدند. در نهايت، با حذف يرسشنامه هاى مخدوش و داده هاى دورافتاده، الم مورد از اين يرسشنامه ها وارد تحليل شد و نمونه يثوهش را تشكيل دادند. ابزارهاى جمع آورى داده ها در اين يزوهش عبارت بودند از: 1 - نسخه فارسى مقياس دشوارى در نظم بخشى هيجانى: اين مقياس يك ابزار خودَزارشى سب گويه اي است كه و دشوارى در نظه بخشى هيجانى، شامل نيذيرفتن ياسخ هاى هيجانى، دشوارى

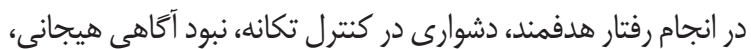
دسترسى محدود به راهبردهاى نظه بخشى هيجانى و نبود وضوح هيجانى، را با استفاده از يك مقياس ه درجه ایى ليكرتى ارزيابى مى كند. گراتز و روئمر در سال ع +.بr نسخه اصلى اين مقياس را تدوين كردند و با استفاده از تحليل عاملى روايى اين مقياس را بررسى رسى

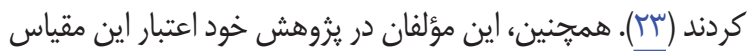
با استفاده از ضريب آلفاى كرونباخ را براى هر شش زيرمقياس بالاى

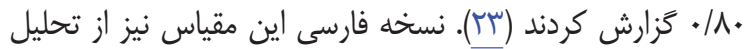
عامل نسخه اصلى در جمعيت ايرانى تدوين شده است (أب). خانزاده و همكاران (זب) ساختار عاملى و روايى سازه اين مقياس را با استفاده از تحليل عامل اكتشافى و روايى ملاكى آن را با محاسبه همبستخى اين مقياس با سياهه هاى افسردگى و اضطراب بك بررسى كردند. در اين يزوهش، اعتبار زيرمقياس هاى نسخه فارسى اين مقياس نيز با استفاده از ضريب آلفاى كرونباخ و ضريب بازآزمايى يس از يك يك

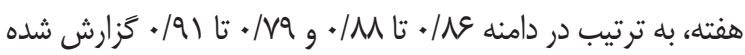




\begin{tabular}{|c|c|c|c|c|}
\hline \multicolumn{2}{|l|}{ زنان } & \multicolumn{2}{|l|}{ مردان } & \multirow{2}{*}{ تحصيلات } \\
\hline درصد فراوانى نسبى & فراوانى & درصد فراوانى نسبى & فراوانى & \\
\hline$\Delta \Delta / 1$ & 11 & $f \cdot / f$ & Rt & سيكل \\
\hline TI/r & iq & ل & щর & دييلم \\
\hline$N / r$ & ir & $1 . / 8$ & 11 & فوق دييلم \\
\hline$r / 1$ & 9 & $\Lambda / V$ & 9 & ليسانس \\
\hline $1 / \mu$ & r & $r / \Lambda$ & r & فوق ليسانس و بالاتر \\
\hline $1 .$. & IIV & $1 .$. & 1.4 & كل \\
\hline
\end{tabular}

در كام نخست، براى بررسى ارتباط بين شدت و مدت درد آمده است. همانكَونه كه (جدول ب) نشان مى دهد، مدت و شدت درد

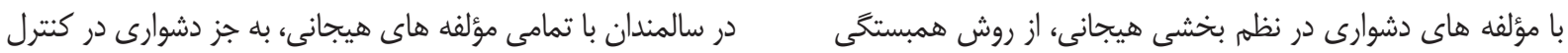
بيرسون استفاده شد. نتايج حاصل از بررسى همبستكى بين اين إنى

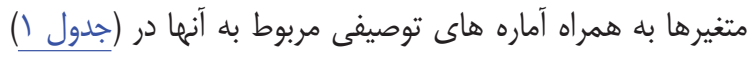
جدول ז: ماتريس همبستخى، آماره هاى توصيفى و اعتبار متغيرهاى يثوهش (جدول

\begin{tabular}{|c|c|c|c|c|c|c|c|c|c|c|c|}
\hline يايايى & \multicolumn{2}{|c|}{ آماره هاى توصيفى } & \multicolumn{8}{|c|}{ همبستخى بين متغيرهاى يزوهش } & \\
\hline آلفا & SD & $\mathrm{M}$ & $\wedge$ & V & $\varepsilon$ & $\Delta$ & f & $r$ & $r$ & 1 & \\
\hline $\begin{array}{l}--- \\
+/ 91 \\
\cdot / \Lambda . \\
\cdot / V Q \\
\cdot / V A \\
\cdot / V G \\
.|A| \\
\cdot / \mathrm{V} .\end{array}$ & $\begin{array}{l}\mid r \cdot / r q \\
\mid N / F q \\
q / V \mid \\
r / \Delta \Delta \\
\Delta / q \mid \\
\Delta / \mid \Lambda \\
\Delta / q V \\
r / \mu \mid\end{array}$ & 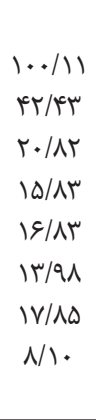 & 1 & $\begin{array}{c}1 \\
\cdot 10 \cdot * * * 1\end{array}$ & $\begin{array}{c}1 \\
\cdot / / \gamma^{* *} \\
\cdot / T V^{* * *}\end{array}$ & $\begin{array}{c}1 \\
. / 4 Y^{* *} \\
. / 99^{* * *} \\
. / 4 \cdot * *\end{array}$ & 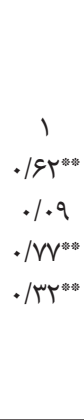 & 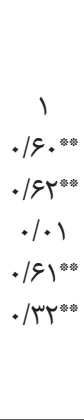 & 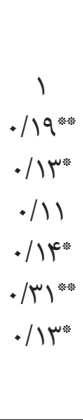 & 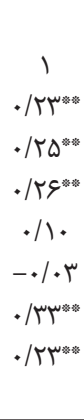 & 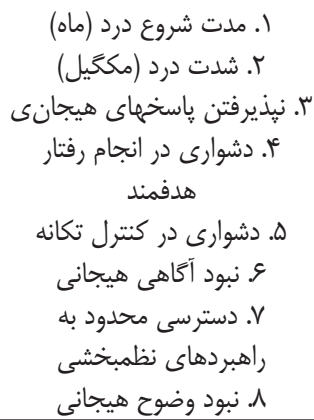 \\
\hline
\end{tabular}

$* \mathrm{P}>0 / 05 \quad * * \mathrm{P}<0 / 01$

به علاوه، (جدول r)، علاوه بر همبستى و وآماره هاى بخشى هيجانى در ييشيينى شدت و مدت درد در سالمندان، از روش

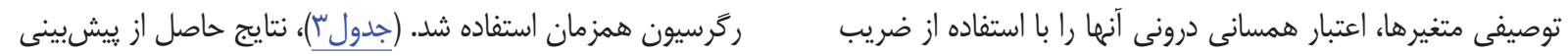

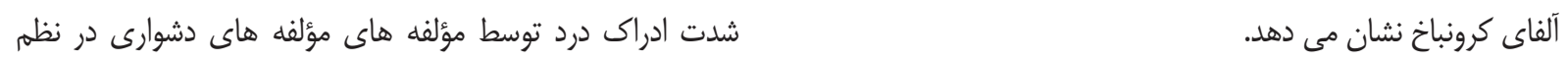
در كام بعدى، براى بررسى نقش مؤلفه هاى دشوارى در نظم بخشى هيجانى را نشان مى دهات جدول سا: شاخص ها و ضرايب ركرسيون ييشيبنى شدت ادراك درد در سالمندان

\begin{tabular}{|c|c|c|c|c|c|c|c|}
\hline \multicolumn{2}{|c|}{ تحليل واريانس } & \multicolumn{5}{|c|}{ شاخصما و ضرايب ركرسيون } & \multirow{2}{*}{ يبشبينى كننده } \\
\hline sig & $\mathrm{F}$ & $\mathrm{R}^{r}$ & $\mathrm{R}$ & sig & $\mathrm{t}$ & $\beta$ & \\
\hline 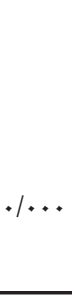 & $9 \% / V$ &.$/ \mathrm{V}$ &.$|4|$ & 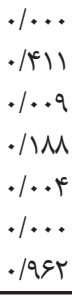 & 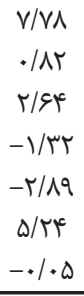 & $\begin{array}{l}\cdot / \cdot 9 \Lambda \\
\cdot / r \Delta t \\
-\cdot / 11 \Lambda \\
-\cdot / 1 A T \\
\cdot / \Delta V \cdot \\
-\cdot / \cdot+r\end{array}$ & 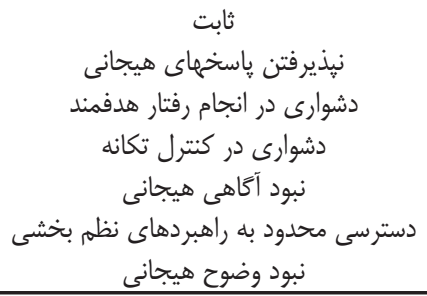 \\
\hline
\end{tabular}

$$
\text { متغير وابسته: شدت كلى درد }
$$


نتايج (جدول ؟) نشان مى دهد كه به طور كلى مؤلفه هاى سالمندان دارند.

توسط مؤلفه هاى مؤلفه هاى دشوارى در نظم بخشى هيجانى را

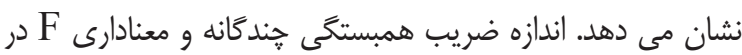
اين تحليل نشان مى دهد كه مؤلفه هاى دشوارى در نظم بخشى هيجانى به طور كلى مى توانند مدت شروع درد را ييشيينى كنند و بيش از سا درصد از تغييرات آن را تبيين كنند.
(جدول٪) نيز، نتايج حاصل از ييشبينى مدت شروع درد

دشوارى در نظم بخشى هيجانى قادر به ييشبينى شدت ادراك درد

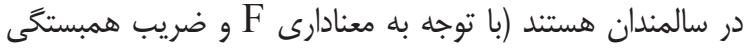

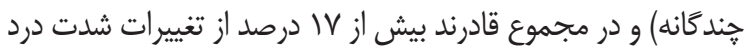
را اييشبينى كنند. همجنين، با توجه به معنادارى ضر ايب بتا، اين نتايج نشان مى دهد كه از بين 9 مؤلفه دشوارى در نظم بخشى هيجانى، دسترسى محدود به راهبردهاى نظم بخشى، دشوارى در انجام رفتار

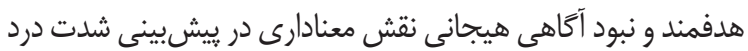
جدول f: شاخص ها و ضرايب ركَ سيون براى بيشبينى مدت شروع درد در سالمندان

\begin{tabular}{|c|c|c|c|c|c|c|c|}
\hline ريانس ب ري & تحليل & & & كر ايب رً & كاخصهاو & & مدل \\
\hline sig & $\mathrm{F}$ & $\mathrm{R}^{r}$ & $\mathrm{R}$ & sig & $\mathrm{t}$ & $\beta$ & بيشيينى كننده \\
\hline$\cdot \ldots$ & $9 \Delta / \Delta$ & ז & g & $\begin{array}{l}. / \ldots \\
. / 194 \\
. / r \cdot 1 \\
. / \cdot V \mu \\
. / \% q 1 \\
. / \ldots \\
. / 1 / \mu\end{array}$ & 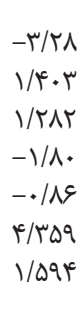 & $\begin{array}{l}. / 1 M F \\
. / 1 F A \\
-. / 194 \\
-. / 0 Q 99 \\
. / T M A \\
. / 1 T T\end{array}$ & 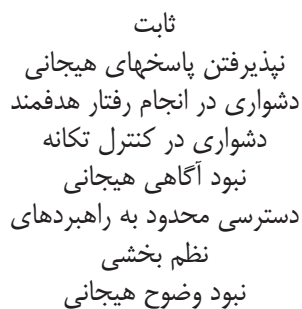 \\
\hline
\end{tabular}

متغير وابسته: مدت زمان شروع درد

ساختارى استفاده شد كه در آن دشوارى در نظم بخشى هيجانى علاوه بر اين، نتايج (جدول ع) نشان مى دهد كه از بين

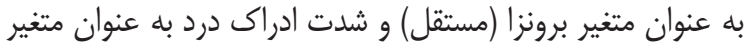
مؤلفه هاى دشوارى در نظم بخشى هيجانى، تنها دسترسى محدود درونزا (وابسته)، و زيرمقياسهاى هر يك از اين سازه ها به عندان عنوان

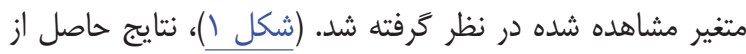
مدلسازى معادلات ساختارى براى بررسى روابط بين سازه هاى
به راهبردهاى نظم بخشى به طور معنادارى قادر به يِيشبينى مدت شروع درد در سالمندان مى باشد. در گام پايانى، براى بررسى مدل ساختارى رابطه بين سازه هاى دشوارى در نظم بخشى هيجانى و شدت ادراى درد در سالمندان در سطح متغيرهاى مكنون، از روش مدلسازى معادلات

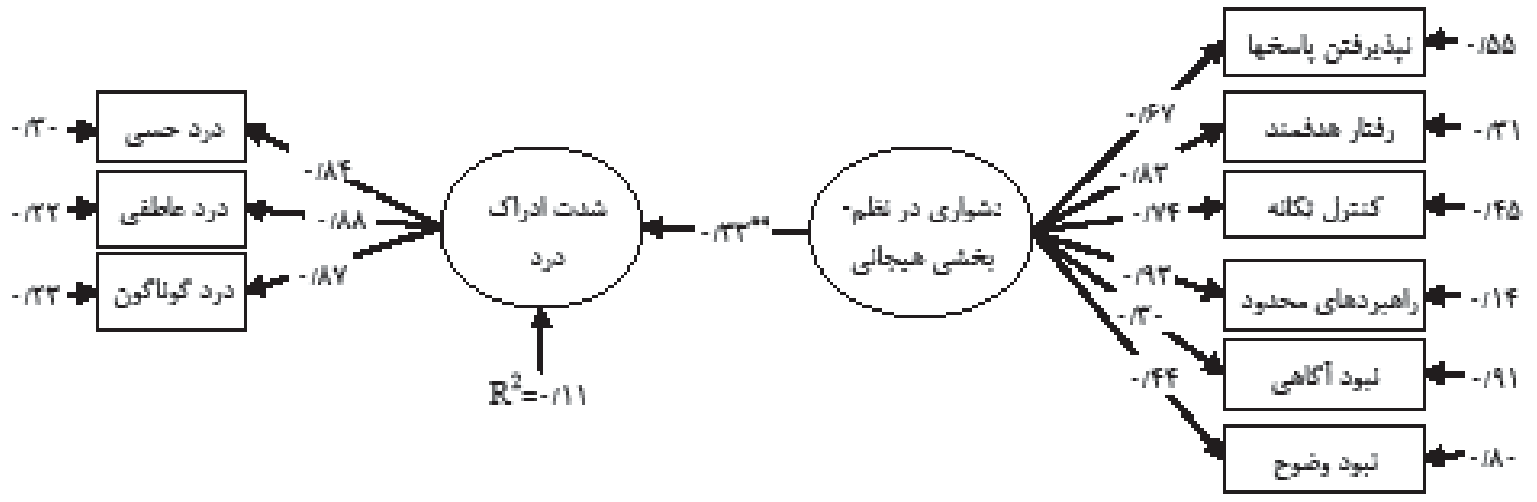

شكل (: مدل ساختارى رابطه بين دشوارى در نظه بخشى هيجانى و شدت ادراك درد در سالمندان

نتايج حاصل از مدلسازى معادلات ساختارى در (شكل (1) بر آن تأثير مى كذارد.

در نهايت، به منظور بررسى برازش مدل ارائه شده درد

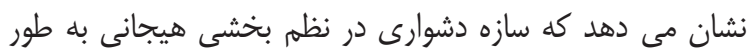

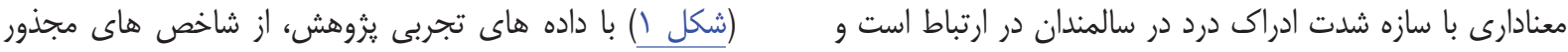


مقايسه اى (NFI)، ريشه دوم ميانكين خطاى تقريب(RMSEA)، ريشه دوم ميانگين باقيمانده (RMR) و ريشه دوم ميانكين باقيمانده معيار شده (SRMR) استفاده شد. نتايج حاصل از بررسى برازش دئان مدل ساختارى ثروهش در (جدول ه) آمده است.
خى (Kr)، مجذور خى بر درجه آزادى (Kr/df)، شاخص نيكويى برازش (GFI)، شاخص نيكويى برازش تعديل شده (AGFI)،

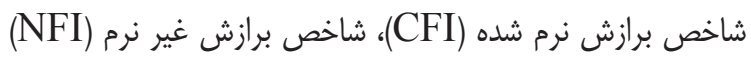

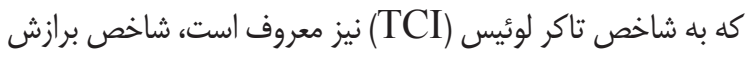

جدول ه: شاخص هاى برازندگى مدل ساختارى رابطه بين دشوارى در نظم بخشى هيجانى و شدت ادراى درد در سالمندان

\begin{tabular}{|c|c|c|c|c|c|c|c|c|c|c|c|c|}
\hline \multicolumn{3}{|c|}{ شاخصهاى ديخر } & \multicolumn{3}{|c|}{ شاخصهاى مقايسهاى } & \multicolumn{6}{|c|}{ شاخصهاى مطلق } & \multirow[b]{2}{*}{ شاخصهاى برازندكى } \\
\hline SRMR & RMR & $\begin{array}{l}\text { RM- } \\
\text { SEA }\end{array}$ & CFI & TLI & NFI & AGFI & GFI & $\mathrm{K}^{r} / \mathrm{df}$ & df & $\mathrm{P}$ & $\mathrm{K}^{r}$ & \\
\hline $.1 .+\Delta$ & $1 / r V$ & $.1 . \Delta \Lambda$ & .191 &.$/ 9 \mathrm{~V}$ &.$/ 9 V$ & .194 &.$/ 98$ & |/द & IV & $\cdot 1 \cdot \Delta \Delta$ & תוT/K & اندازه شاخصمها \\
\hline
\end{tabular}

كه در زمان رويارويى با هيجانات مشكل، آكاهانه از راهبردهاى

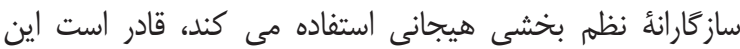
هيجانات را به خوبى مديريت كند و درگير رفتارهاى هدفمند شود. راهبردهاى مورد استفاده براى نظه بخشى هيجانات دربردارنده طيف

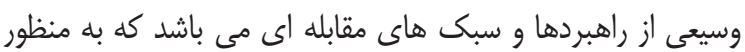
كاهش ادراك و شدت درد به كار مى رود. اين راهبردها شامل توجه برگردانى، تفسير مجدد احساس درد، فاجعه سازى، ناديده انغًارى احساس درد، دعا خواندن يا اميدوارى، استفاده از خودكويى هاى

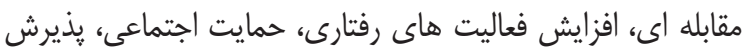

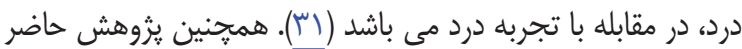
نشان مى دهد كه راهبردهاى نظم بخشى هيجانى ناساز گارانه، مانند

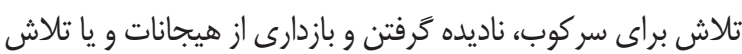
براى كنترل بيش از حد هيجانات از طريق نخرانى، نشخوار فكرى و وسواس هاى فكرى، كه تحت عنوان دسترسى محدود به راهبردهاى نظم بخشى هيجانى در يُوهش حاضر آمده است، منجر به افزايش شدت و ادراك درد مى شود. هر خند استفاده از راهبرد سركوب كردن در كوتاه مدت باعث مى شود كه فرد بتواند درد را بهتر تحمل كند، اما با اين وجود استفاده از اين راهبرد در بلند مدت موجب ادراك درد

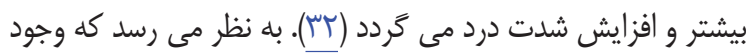
آَاهى هيجانى در مورد هيجانات منفى همراه با درد، مانند خشم،

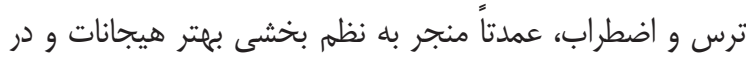
نهايت سازگًارى بهتر درد مى شود، اما از سوى ديخر، به نظر مى رسد

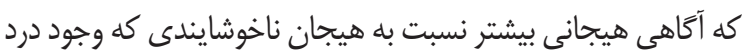

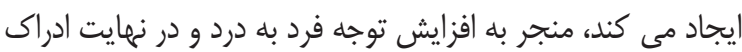
بيشتر درد مى شود. به عبارت ديخر، علاوه بر ادراك درد، انتظار درد نيز مىتواند ظرفيت يردازش اطلاعات مثبت را كاهش دهد (سب). لذا

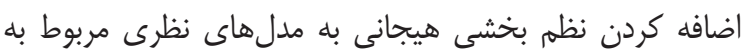
درد مىتواند به روشن شدن اين مساله كمك كند كه هرا برخى
شاخص خى دو برازش مدل را به صورت كلى بررسى مى كند

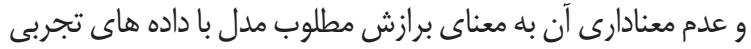

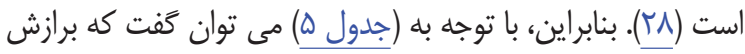
مدل حاضر در حد مطلوبى است. همجرنين، منابع مختلف در زمينه

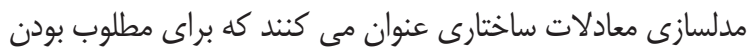
برازش مدل، شاخص هاى CFI و GFI، AGFA، NFI، TCI بايد بين 9/ • و ا قرار داشته باشند و هر هُ هـ به عدد يك نزديكتر

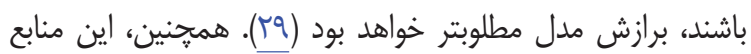

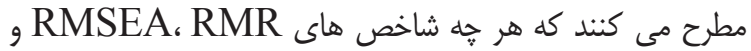

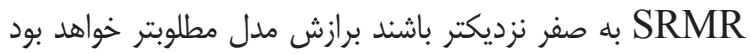

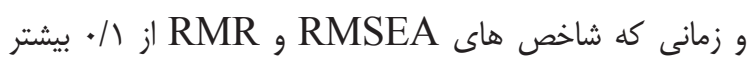
باشند برازش ضعيف و هر خه از ^•|• پايينتر باشد برازش مطلوبتر

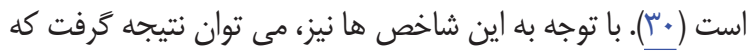

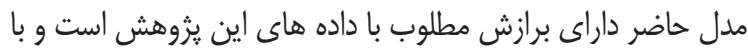
اطمينان بالايى مى توان اين مدل را يذيرفت.

به طور كلى، نتايج حاصل از يزوهش حاضر نشان مى دهند كه دشوارى در نظم بخشى هيجانى با شدت ادراك درد در سالمندان در ارتباط است و با افزايش نقايص و دشوارى ها در اين زمينه، شدت هـ بـات ادراك درد در اين گروه سنى افزايش مى يابد. همجنين، اين نتايج نشان داد كه از بين مؤلفه هاى دشوارى در نظهم بخشى هيجانى، دسترسى محدود به راهبردهاى نظه بخشى، دشوارى در انجام رفتار

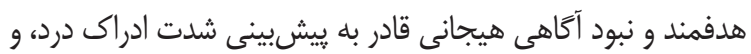
دسترسى محدود به راهبردهاى نظم بخشى قادر به يِيشينى مدت شروع درد در سالمندان مى باشد. اين يافته با نتايج يثوهشىهاى

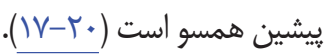
در تفسير اين يافتهها مىتوان به هند نكته اشاره كرد. افرادى 
نمونه كيرى اشاره كرد. همجنين در مدل حاضر نقش متغيرهاى جمعيت شناختى مورد بررسى قرار نخرفت. با توجه به متغيرهايى همجون سن، جنسيت و حمايت اجتماعى مىتوانند در تبيين

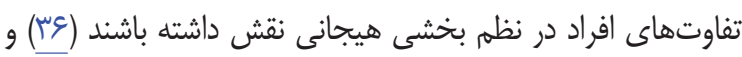
بنابراين توجه به آنها در مطالعات آينده حائز اهميت است.

\section{نتيجه كَيرى نهائى}

در مجموع يافتهاى يزوهش حاضر نشان دهنده اهميت نظم بخشى هيجانى در ادراك درد سالمندان بود. اين يافته از اين نظر مىتواند براى درمانكران حائز اهميت باشد كه دشوارى در نظم بخشى هيجانى علاوه بر ادراك درد، مىتواند افت عملكرد و استفاده از راهبردهاى مقابله اى نامناسب همجيحون سوء مصرف مواد را بهانه

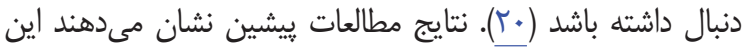

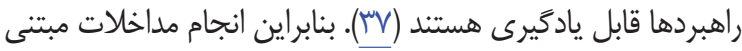
بر هيجان در افر اد مبتلا به درد مزمن ضرورى به نظر مىرسد.

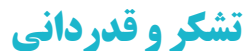

$$
\begin{aligned}
& \text { نويسندكان به اين وسيله قدردانى خود را از كليه سالمندانى كه } \\
& \text { در يزوهش حاضر مشاركت داشتند اعلام مى دارند. }
\end{aligned}
$$

\section{References}

1. Grant, J. A., \& Rainville, P. (2009). Pain sensitivity and analgesic effects of mindful states in Zen mediators: A cross-sectional study. Psychosomatic Medicine, 71, 106114.

2. Gatchel, R. J., \& Turk, D. C. (1999). Psychosocial Factors in Pain. New York: Guilford.

3. Grant, J. A., \& Rainville, P. (2009). Pain sensitivity and analgesic effects of mindful states in Zen mediators: A cross-sectional study. Psychosomatic Medicine, 71, 106114.

4. Helme, R. D., \& Gibson, S. J. (2000). Epidemiology of Pain. In Crombie, I. K., Croft, P. R., Linton, S. J., et al (Eds), Pain in Older People. Seattle: IASP Press. (pp. 1529).

5. Gibson, S.J. (2003). Pain and aging: the pain experience over the adult life span. In: Dostrovsky, J.O., Carr, D.B., Koltzenburg, M. (Eds.), Progress in Pain Research and
افراد آسيب يذيرى بيشترى نسبت به درد دارند و هُكَونه مى توان اين آسييب يذيرى را از طريق مداخلات درمانى كاهش داد (19).

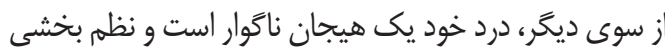
هيجانى مىتواند در تسكين درد نيز موثر واقع شود. مرسكى (بَّ)

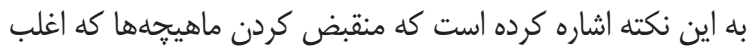
به تجربه درد شديد همراه است، مىتواند خود به عنوان يكى از علتهاى درد در نظر گرفته شود و در تشديد اين تجربه نقش داشته باشد.

به طور كلى، آكاهى هيجانى به معناى اجتناب نكردن از

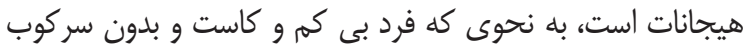

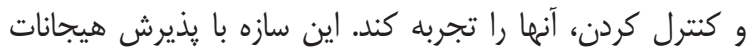

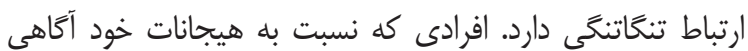
دارند، راحت تر و بهتر مى توانند هيجانات خود را بيذيرند كه در نهايت باعث مى شود فرد بر هيجاناتش كنترل بيشترى داشته باشد (هـآ). استفاده از راه كارهاى ناكارآمد براى تنظيم هيجانات، مانند نشخوار

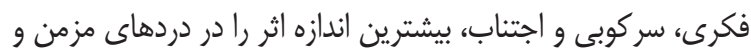

$$
\text { اختلالات روانى دارند (بآ). }
$$

مطالعه حاضر با محدوديتهايى نيز همراه بود كه در تفسير يافتهها بايد مورد توجه قرار گيرند. از جمله اين محدوديتها مىتوان به خودَّزارشى بودن ابزارهاى بزوهش و در دسترس بودن روش

Management. Seattle: IASP Press. (pp. 178 - 221).

6. American Geriatric Society. (AGS). (2002). The management of persistent pain in older persons. AGS Panel on Persistent Pain in Older Persons. Journal of the American Geriatric Society, 50, S205-S224.

7. Harkins, S. W. (1996). Pain perceptions in the old. Clinical Geriatric Medication, 12, 435 - 446.

8. 8. Helme, R. D., \& Gibson, S. J. (2000). Epidemiology of Pain. In Crombie, I. K., Croft, P. R., Linton, S. J., et al (Eds), Pain in Older People. Seattle: IASP Press. (pp. 1529).

9. Gross, J. J., \& Thompson, R. A. (2007). Emotion regulation: Conceptual foundations. In J. J. Gross (Ed.), Handbook of Emotion Regulation. New York:Guilford Press. (pp. 3 - 24)

10. Villemure, C., \& Bushnell, M. C. (2002). Cognitive modulation of pain: how do attention and emotion influence pain 
processing? A topical review. Pain, 95, 195 199.

11. Rhudy, J. L., Williams, A. E., McCabe, K. M., Nguyen, M. A. T. V., \& Rambo, P. (2005). Affective modulation of nociception at spinal and supraspinal levels. Psychophysiology, 42, 579-87.

12. Leahy, R. L. (2010). Emotional schemas and resistance to change in anxiety disorders. In D. Sookman, \& R. L. Leahy (Ed.), Treatment resistant anxiety disorders. New York: Routledge. (pp. 135-160).

13. Aldao, A., Nolen-Hoeksema, S., \& Schweizer, S. (2010). Emotion-regulation strategies across psychopathology: A meta-analytic review. Clinical Psychology Review, 30, 217-237.

14. Gratz, K. L., \& Roemer, L. (2004). Multidimensional assessment of emotion regulation and dysregulation: Development, factor structure, and initial validation of the Difficulties in Emotion Regulation Scale. Journal of Psychopathology and Behavioral Assessment, 26, 41-54.

15. Keefe, F. J., Lumley, M., Anderson, T., Lynch, T., \& Carson, K. (2001). Pain and emotion: New research directions. Journal of Clinical Psychology, 57, 587-607.

16. Innes, S. I. (2005). Psychosocial factors and their role in chronic pain: A brief review of development and current status. Chiropractic \& Osteopathy, 13 (6), 1-5.

17. Connelly M, Bromberg MH, Anthony KK, Gil KM, Franks L, Schanberg LE. Emotion regulation predicts pain and functioning in children with juvenile idiopathic arthritis: an electronic diary study. J Pediatr Psychol. 2012; 37 (1): 43-52.

18. Agar-Wilson M, Jackson T. Are emotion regulation skills related to adjustment among people with chronic pain, independent of pain coping?. Eur J Pain. 2012; 16 (1):10514.

19. Koechlin H, Coakley R, Schechter N, Werner C, Kossowsky J. The role of emotion regulation in chronic pain: A systematic literature Review. Journal of Psychosomatic Research 2018; 107: 38-45.

20. Lutz J, Gross RT, Vargovich AM. Diculties in emotion regulation and chronic pain-related disability and opioid misuse. Addictive Behaviors. 2018; 87: 200-205.

21. Perlman, D. M., Salomons, T. V., Davidson, R. J., \& Lutz, A. (2010). Differential Effects on Pain Intensity and Unpleasantness of Two Meditation Practices. Emotion, 10 (1), 65-71.

22. Mc Cracken, L.M., \& Eccleston, C. (2005). A prospective study of acceptance and patient functioning with chronic pain. Pain, 118, 164-169.

23. Gratz, K. L., \& Roemer, L. (2004). Multidimensional assessment of emotion regulation and dysregulation: Development, factor structure, and initial validation of the Difficulties in Emotion Regulation Scale. Journal of Psychopathology and Behavioral Assessment, 26, 41-54.

24. Khanzadeh M, Saeidian M, Hosseinchary, Edrisi F. Factor structure and psychometric properties of difficulties in emotional regulation scale. Journal of behavioral sciences. 6 (1): 87-96. (persian).

25. Turk, D. C., Rudy, T. E., \& Salovey, P. (1985). The McGill Pain Questionnaire reconsidered: Confirming the factor structure and examining appropriate uses. Pain, 21, 385-397.

26. Miller, T. W., \& Kraus, R. (1990). An overview of chronic pain. Hosp Community Psychiatry, 41 (4), 433- 440.

27. Khanzadeh M. Prediction of pain perception based on emotional schemas and difficulties in emotion regulation. MA thesis. Shiraz University. 2011. (persian).

28. Jaccard, J. \& Wan, C. K. (1996). LISREL Approaches to Interaction Effects in Multiple Regression. CA: Sage.

29. Schreiber, J. B., Stage, F. K., King, J., Nora, A. \& Barlow, E. A. (2006). Reporting Structural Equation Modeling and Confirmatory Factor Analysis Results: A Review. The Journal of Educational Research. 99 (6), 323-337.

30. McCallum, R. C., Browne, M. W. \& Sugawara, H. M. (1996). Power Analysis and Determination of Sample Size for Covariance Structure Modeling. Psychological Methods. 1 (12), 149-160. 
31. Tull, M. T., Gratz, K. L. (2008). Further examination of the relationship between anxiety Sensitivity and depression: The mediating role of experiential avoidance and difficulties engaging in goal-directed behavior when distressed. Journal of Anxiety Disorders. 22, 199-210.

32. Van Middendorp, H., Lumley, M. A., Moerbeek, M., and et al. (2010). Effects of anger and anger regulation styles on pain in daily life of women with fibromyalgia: A diary study. European Journal of Pain, 14, 176-182.

33. Zautra AJ. Emotions, stress, and health. New York: Oxford University Press. 2003.

34. Merskey H. Psychological and psychiatric aspects of pain control. In: Smith WL, Merskey H, Gross SC, Smith WL, Merskey $\mathrm{H}$, editors. Pain: meaning and management. New York: SP Medical and Scientific Books; 1980. 105-17.

35. Leahy, R. L. (2002a). A model of emotional schemas. Cognitive and Behavioral Practice, 9, 177-190.

36. Paquet C, Kergoat MJ, Dube L. The role of everyday emotion regulation on pain in hospitalized elderly:Insights from a prospective within-day assessment, Pain. 2005; 115: 355-363.

37. Davis EL, Levine LJ. Emotion regulation strategies that promote learning: reappraisal enhances children's memory for educational information, Child Dev. 2013; 84 (1): 361374. 